\title{
DIFICULDADE DE LEITURA E ESCRITA NOS ANOS INICIAIS DO ENSINO FUNDAMENTAL I
}

Josemery Alkmim Vieira de Brito*

\section{RESUMO}

O presente artigo discorre sobre a DIFICULDADE DE LEITURA E ESCRITA NOS ANOS INICIAIS DO ENSINO FUNDAMENTAL I, com o objetivo de analisar as dificuldades do processo de ensino-aprendizagem da leitura e escrita nos anos iniciais. Além da pesquisa bibliográfica, foi utilizada a técnica da pesquisa de campo, com a utilização de questionário de pesquisa, esta última com a análise qualiquantitativa dos dados obtidos numa escola pública. Foi analisada uma amostra de 10 professores do Ensino Fundamental I. A pesquisa revelou alguns equívocos por parte dos professores, como a associação da aula como o "local de estudo", descuido com a lição de casa, excesso de cuidado com planejamento pedagógico e pouco uso de técnicas de estimulação/motivação dos alunos. Partindo da premissa de que o conhecimento não é um produto ofertado exclusivamente pelo professor e, tendo em vista que é preciso ensinar aos alunos a estudarem em casa, com o apoio da família, conclui-se que no processo ensino/aprendizagem deve-se observar o ciclo: aula, estudo e uma boa noite de sono.

Palavras-Chave: Alfabetização. Dificuldades de leitura. Ensino-aprendizagem. 


\section{INTRODUÇÃO}

Aprender a ler e a escrever é de fundamental importância para o desenvolvimento do indivíduo e da sociedade. Nos dias atuais, a Educação enfrenta problemas: os discentes não têm o hábito do estudo após a aula, são seduzidos pela imagem, pelo imediatismo, pela publicidade, propagados pelos mais diversos meios de comunicação.

As dificuldades de leitura e escrita nos anos iniciais do ensino fundamental constituem um elemento fundamental no planejamento escolar. As dificuldades permitem prever os processos de uma atividade que contribue de maneira adequada para a aprendizagem. Segundo Piazzi (2014) o ciclo de aquisição do conhecimento passa por três fases: entender, aprender e fixar.

Uma forma interessante de despertar o gosto da leitura é: contar história usando recursos audiovisuais, pois as crianças são visuais, auditivas e cinestésicas. O professor precisa descobrir a melhor forma de ensinar o prazer pela leitura.

O professor alfabetizador deve estimular as crianças a ler como uma forma de lazer, entretenimento e diversão. É um momento mágico. No fundo todas as crianças gostam de ler, pois os livros contam histórias de vida, só que elas não sabem disso. Precisam ser estimuladas.

Para alcançar os objetivos propostos foi feito um questionário com perguntas abertas e fechadas aos educadores do primeiro ciclo de alfabetização.

$O$ interesse em obter maior conhecimento sobre as dificuldades do ensino/aprendizagem de leitura e escrita nos anos iniciais do ensino fundamental I move esta investigação, cujo resultado é interessante para a Escola, ao analisar elementos para a tomada de decisões, como capacitação de professores e orientação da importância da tarefa após a aula desde os anos iniciais do ensino fundamental. 


\section{PROCESSO DE ENSINO/APRENDIZAGEM}

\subsection{Leitura, Escrita e Escola}

Todo ser humano nasce com potencial para aprender, necessitando apenas de estímulos externos. Um dos desafios do educador é oportunizar aos educandos diversidade de atividades, motivando-os à aprendizagem.

A democratização do acesso à escola não foi o suficiente para superar o índice de analfabetismo no Brasil. A exploração deficiente da linguagem escrita no cotidiano das crianças, principalmente nos municípios mais pobres, faz com que elas sintam mais dificuldade de aprender a ler e escrever.

Há necessidade de mudança nas práticas do professor para atender a estas crianças. Os professores têm uma grande ferramenta, que é despertar no aluno o gosto pela leitura através do lúdico, proporcionando momentos de prazer pelo ato da leitura constante.

(...) o processo de alfabetização tem no alfabetizando o seu sujeito. O fato de ele necessitar da ajuda do educador, como ocorre em qualquer relação pedagógica, não significa dever a ajuda do educador anular a sua criatividade e a sua responsabilidade na construção de sua linguagem escrita e na leitura desta linguagem. (FREIRE,1989, p.28-29)

Sendo assim, o educador precisa ser um grande leitor para poder oferecer variedade de leitura durante suas aulas. Em adição, o docente precisa ser um pesquisador sempre disposto a conhecer sua turma e cada aluno de acordo com o seu contexto de vida, nas suas particularidades.

Em relação às crianças das classes populares, ou então, menos escolarizadas, incube a questão da escrita. Talvez a escola seja o único lugar para que ocorra esse aprendizado, por isso o educador deve ser competente para ensinar essa tecnologia maravilhosa, pois essas crianças não têm em casa pessoas que as estimulem a gostar de escrever. Essa função é uma especificidade do professor.

A expectativa do professor é de que todas as crianças sejam alfabetizadas dentro de um determinado tempo. Mas cada criança tem seu ritmo, seus interesses, curiosidades e expectativas. Hoje, fala-se em alfabetizar letrando, por isso faz-se necessário que o pedagogo tenha um conhecimento profundo desses conceitos. Nos dias atuais, não se admite mais ensinar como há décadas. 
Sabemos que ao longo do tempo a alfabetização passou por várias mudanças no que se refere às práticas, concepções e necessidades da sociedade. Há algumas décadas bastava aprender assinar o nome e decodificar letras, palavras e frases, que já estava alfabetizado.

$\mathrm{Na}$ perspectiva do letramento deve-se valorizar o conhecimento da prática social. De acordo Assola at all (2015-2016) a alfabetização e o letramento são necessários para compreender a sociedade e desenvolver habilidade para a participação na vida social. Além disso, eles apontam que o professor deve:

(....)compreender que para se Alfabetizar letrando o professor deve garantir o acesso dos alunos a vários tipos de leitura e escrita, com diferentes gêneros textuais de modo que os mesmos compreendam as características e a linguagem utilizadas ao escrever os diferentes tipos de textos, bem como suas funções sociais. (ASSOLA; BORGES; MARQUES; 2015-2016, p.9)

Para os autores, o alfabetizador deve oportunizar aos alunos os vários tipos de leitura e escrita, ainda que não estejam alfabetizados. Deve-se também proporcionar momentos de reflexão da leitura e escrita no contexto da vida social. Neste contexto, Assola at all $(2016$, p.4) afirma que "a alfabetização se põe pelo domínio do código da escrita nas práticas de leitura e escrita, em que o letramento é definido a partir do desenvolvimento de habilidades para o uso adequado da leitura e escrita nas práticas sociais".

Portanto, são processos que ocorrem simultaneamente pelo sistema de escrita alfabético, fonema-grafema nas práticas de leitura e escrita e pelo letramento nas atividades de diferentes gêneros textuais, com diferentes funções que a leitura e escrita exercem no nosso cotidiano.

Muitas vezes a criança interrompe a aula com curiosidade do dia-a-dia. $\mathrm{O}$ professor não dá atenção porque tem um currículo a seguir e o aluno vai perdendo o interesse do conteúdo, achando que a escola é contrária à sua vida e seus desejos. Dentro da sala de aula o que mais importa é o currículo.

As crianças guardam perguntas dentro de $\mathrm{si}$, bem como toda a sua vontade de entender a vida, a morte, a natureza, os animais. Quando é que elas terão respostas? O professor precisa estar atento às indagações do aluno e, partir daí, ensinar a ler e a escrever. O educador precisa entender que a Alfabetização está em constante mudança. 
Defender Alfabetizar letrando pressupõe uma reflexão da teoria que sustenta a prática do professor no momento do ensino da leitura e escrita. Deve-se conhecer a cultura e a ambiência do aluno para que seus conhecimentos passem a ser valorizados pelo professor através dos conhecimentos prévios.

Não é só a cobrança da sociedade que restringe a experiência da aprendizagem na escola, é também a consciência do professor que só lida com o conhecimento acumulado pela sociedade onde se valoriza só o que está nos livros. O professor precisa ser um profissional de sentido, pois sua profissão está ligada ao amor e a esperança. Com base em Gadotti (2003), diz o autor:

\begin{abstract}
A esperança para o professor, a professora, não é algo vazio, de quem espera acontecer. Ao contrário, a esperança para o professor encontra sentido na sua própria profissão, a de transformar pessoas, a de construir pessoas, e alimentar, por sua vez, a esperança delas para que consigam, por sua vez, construir uma realidade diferente, mais humana, "menos feia, menos malvada", como costumava dizer Paulo Freire. Uma educação sem esperança não é educação. (GADOTTI, 2003, p. 70)
\end{abstract}

O educador precisa encorajar a sua esperança diariamente para que busque sentido na sua profissão. Esperança sem ação é morta.

Por isso, acredito que o professor esperançoso deve considerar, não apenas o conteúdo programático para compreensão da leitura e escrita, mas também as características individuais e experiências emocionais dos diferentes sujeitos sociais, através do modo como se expressa e dialoga.

O mundo está lá fora. As perguntas devem deixar para depois. O que é então que vai instigar a vontade de aprender a ler e escrever durante os primeiros anos de escolarização? Os pequenos textos, as cantigas de roda, as músicas. As brincadeiras devem fazer parte do contexto de vida das crianças para que possam ver sentido no aprender a ler e a escrever. Desse modo a vida estará ligada à escola como algo complementar e indissociável.

A educação só tem sentido como vida. Ela é vida. A escola perdeu o seu
sentido de humanização quando ela virou mercadoria, quando deixar se ser
o lugar onde a gente aprende a ser gente, para tornar-se o lugar onde as
crianças e os jovens vão para aprender a competir no mercado. (Gadotti,
2003, p.72)

As crianças das classes populares não têm em casa os jogos, as cantigas de roda, os livros literários que ensinam brincando. Os professores que têm 
conhecimentos especializados precisam alimentar a curiosidade e a vontade de aprender mais com o que está escrito nos livros dando vida ao conteúdo através da sua vida social. Para que isso ocorra, o aluno precisa perceber a relação entre o que está aprendendo na escola e o que aprendeu na instituição familiar.

\footnotetext{
Ele só aprende quando quer aprender e só quer aprender quando vê na aprendizagem algum sentido. Ele não aprende porque é "burrinho". Ao contrário, às vezes, a maior prova de inteligência encontra-se na recusa em aprender. (GADOTTI, 2003, p.47)
}

Assumindo a radicalidade dessa ideia, posso afirmar que nós seres humanos precisamos aprender para vivermos melhor, para nos relacionarmos com o outro. $\mathrm{O}$ educador deve rever as necessidades da aprendizagem no mundo em que vive. $O$ aluno tem essa dificuldade e o professor tem obrigação de ajudar o aluno a perceber isso.

O interesse aumenta sempre que a professora começa a aula antes da leitura e escrita contando, ou mesmo lendo um conto, uma poesia, um poema, advinhas, trava-línguas e outros. Todas as crianças gostam disso, mas dificilmente estas atividades são vistas como uma rotina diária fundamental no processo de aprendizagem.

Certamente se as crianças tivessem a oportunidade de falar sobre os assuntos que despertam sua curiosidade e a respeito dos quais pudessem apresentar suas perguntas, e o educador sempre voltasse as perguntas a elas, sem dá respostas pronta, estaria, assim, estimulando-as a pensar.

E para reforçar essa aula, passa-se uma tarefa que treine leitura e escrita para que guarde na memória. Desta forma poderia aprender com mais facilidade a ler e a escrever. Afinal, só se aprende a fazer fazendo, ler lendo e escrever escrevendo.

\subsection{A Criança e a Escola}

Pensar a relação entre família e escola sempre foi desafiador, principalmente hoje que a estrutura familiar mudou, mas a escola permanece igual há décadas. Nos encontros de conselho de classe percebe-se que o professor culpa a família e a família culpa a escola pelo mau desempenho do aluno. 
Quando se tem harmonia entre escola e família tudo acaba dando certo. Porém, a falta de diálogo tanto na ação do professor quanto nas atitudes dos pais durante a orientação dos seus filhos repercute na aprendizagem das crianças. A família precisa compreender a escola e a escola necessita conhecer seu aluno.

Na maioria das vezes, o ensino é concebido exclusivamente pelo professor e a questão da indisciplina fica com a família. Essa forma de enxergar causa prejuízos na aprendizagem do aluno porque para aprender é necessário atenção e concentração, ou seja, atitudes que dependem do seu comportamento.

Qualquer escola tem seu regimento escolar. Nele está contido as regras e normas que devem ser respeitadas por todos os envolvidos no processo escolar. Considero estas normas como "positivas", pois ensinam as crianças a se comportarem em grupo, a serem pontuais, a ouvirem, a falarem, a respeitarem as diferenças, a reprimirem suas vontades. Condutas estas essenciais para a vida em sociedade.

Sabe-se que cada família tem sua metodologia e ensina regras e valores para as crianças. Aliás, elas possuem várias experiências, pois há regras em casa, nos jogos, nas brincadeiras com os colegas, no trânsito, nos supermercados, nas praças, nos hospitais e tantos mais. É importante ao ensinar as regras, mostrar seus benefícios para que as crianças compreendam o seu valor e as respeitem.

No convívio com os pais, irmãos, primos, tios e tias há uma convivência muito próxima que faz parte da sobrevivência: comer, tomar banho, dormir, arrumar a cama, cuidar dos afazeres domésticos. Essas normas são aprendidas e passadas de geração a geração.

Os livros didáticos dos anos iniciais apresentam textos como: criança não pode trabalhar, criança é só para brincar e estudar. Nesse contexto a família perde a oportunidade de ensinar os filhos a ter função em casa. Para aprender o valor do trabalho precisa saber que ele cansa e tem "valor". Só é digno do trabalho quem se esforça para conquistá-lo. Quem disse que criança não pode arrumar a sua cama? Que só pode estudar?

A família deve resgatar o valor de cada um dentro de casa para que as crianças aprendam a cuidar de todos, e isso se aprende no seu cotidiano. Os princípios devem estar claro na mente dos pais na hora de ensinar a seus filhos. $E$ na escola? O professor também tem um papel fundamental de resgatar o valor da 
leitura e escrita, sendo modelo para o aluno. Como afirma os Parâmetros Curriculares Nacionais (1997)

(...) Além de ser aquele que ensina conteúdos, é alguém que pode ensinar o valor que a língua tem, demostrando o valor que tem para si. Se é um usuário da escrita de fato, se tem boa e prazerosa relação com a leitura, se gosta verdadeiramente de escrever, funcionará como um excelente modelo para os alunos. Isso é especialmente importante principalmente quando eles provêm de comunidades pouco letradas, onde não participam de atos de leitura e escrita junto com adultos experientes. (BRASIL, 1997, p. 48)

Portanto, o professor será uma referência para o aluno, fazendo-lhe perceber o valor da leitura e escrita em sua vida, com sentido e não como apenas uma exigência do professor.

Muitos professores dizem: "A escola é sua", porém não percebem as peculiaridades do universo infantil, sendo incapazes de identificarem as necessidades básicas de uma criança, como a fantasia, os jogos, as brincadeiras, o lúdico. A criança aprende brincando. O educador, na maioria das vezes, vê muita seriedade nos conteúdos e desconsidera o brincar e o conhecimento prévio dos alunos. Há falta de diálogo entre professor e aluno.

O educador deve ser um eterno pesquisador, cada turma é dotada de conhecimentos e culturas diferentes. Cabe ao professor descobrir o melhor caminho para se ensinar.

E o respeito a essa identidade, sem o qual o esforço do educador fraqueja, tem que ver com essa leitura que a criança faz do mundo e com a qual ela chega à escola. É uma leitura que ela aprende a fazer, no convívio da sua casa, no convívio da sua vizinhança, de seu bairro, de sua cidade, com a marca forte de corte de sua classe social. (FREIRE, 2001, p.140)

Portanto, essa leitura que a criança traz é a sua linguagem, a sua sintaxe, isto é, a sua competência linguística. Se acompanharmos mais de perto o comportamento das crianças no dia a dia escolar, poderemos notar que não são as regras que rejeitam, mas a forma como são ditas as solicitações. É necessário que se conheça cada aluno para educá-lo melhor na sua subjetividade, pois cada um aprende de forma diferente.

Segundo Bossa (2013), analisar a possibilidade de aprender implica considerar o desejo de aprender, que trata da energia necessária ao bom funcionamento cognitivo, o equivalente à energia, ou seja, a afetividade que vai determinar o desejo de aprender, atribuindo um valor às atividades que regula a energia. 
É necessário também saber qual é o desejo dessa criança, de repente a criança pode não ter vontade de aprender. $O$ educador precisa compreender esse aluno na sua singularidade, identificando possibilidades de desenvolvê-lo, pois a cada momento a criança interage com o mundo externo, impulsionada por razões emocionais.

\footnotetext{
Por outro lado, uma criança pode não desejar aprender a ler e a escrever, por não querer perder o lugar de bebê na família. Então fará pouco investimento energético para 0 trabalho cognitivo necessário à tal aprendizagem. Logo podemos dizer que tem 0 motor, mas falta 0 combustível para pôr o processo em ação. (BOSSA, 2013, p. 18)
}

Logo, sabe-se que o processo de aprendizagem é único, particular em cada pessoa, porém precisa ser desafiado e estimulado a todo o momento para que 0 aluno busque referencial e sentido do aprender. O educador deve está preparado para diagnosticar a causa do problema e tratar a causadora do sintoma e, se possível, buscar ajuda em outros profissionais.

\subsection{Dificuldade de Aprendizagem na Escola}

Bossa (2013 p.11) define a aprendizagem escolar como um processo natural e prazeroso. Descobrir e aprender devem ser um grande prazer. Se não é, algo está errado. A referida autora afirma que quando se percebe que o aluno tem dificuldade de aprendizagem deve-se identificar a causa e combatê-la para tratar o sintoma.

Nesse contexto, é de fundamental importância o acompanhamento dessa criança junto a um "psicopedagogo", ou seja, junto a um profissional preparado para a prevenção, o diagnóstico e o tratamento dos problemas de aprendizagem escolar.

O psicopedagogo utiliza vários recursos para identificar as causas do problema como: testes, desenhos, histórias, atividades pedagógicas, jogos e brinquedos. Após a identificação do problema, é realizado o plano de prevenção; nesse momento busca-se parceria com os professores para melhorar o ensino-aprendizagem da criança. (BOSSA, 2013)

Entendo que o psicopedagogo é um profissional que tem muito a contribuir para com a educação, pois ele é um especialista no assunto e pode ajudar o professor a buscar a melhor forma de se aprender, evitando danos futuros na vida da criança. (BOSSA, 2013) 
É necessário, ainda, ter compreensão da afetividade, o processo do aprender implica em sujeito que está em harmonia corpo e mente. Precisamos lapidar as emoções dos alunos, trazer vida e sentido para os conteúdos, fundamental na aprendizagem significativa. 


\section{METODOLOGIA DA PESQUISA}

Neste capítulo, exponho o caminho percorrido durante a pesquisa, em seus aspectos qualitativos e quantitativos. Os dados foram colhidos de forma precisa, onde ficou comprovado que as dificuldades derivam de diversas situações. É tarefa do professor identificar suas causas e buscar a melhor alternativa para solucionálas.

A pesquisa de campo foi realizada por meio de questionário de pesquisa, com questões relacionadas ao processo de ensino dos professores, bem como, o confronto das teorias à luz de uma visão teórica e científica com enfoque no contexto educacional para melhor fundamentar e analisar os problemas de aprendizagem.

Foi realizada uma pesquisa bibliográfica, qualitativa, quantitativa, que segue os seguintes passos de ordenação dos dados, classificação e análise final.

O método utilizado foi a entrevista, com técnica exploratória e bibliográfica. Houve leituras e estudos de autores com diferentes pontos de vista acerca da aprendizagem de leitura escrita e possíveis dificuldades no contexto escolar tanto no ensino como na aprendizagem.

A pesquisa bibliográfica foi realizada através de fontes de leitura como: livros, sites, revistas, jornais, artigos, dissertações e teses, que abordam o ensino e a aprendizagem nos anos iniciais do ensino fundamental I. Essa diversidade bibliográfica será muito importante para a abrangência, confiabilidade e validade da pesquisa.

Para Lakatos e Marcondes (2003, p.183) "a pesquisa bibliográfica não é mera repetição do que já foi dito ou escrito sobre certo assunto, mas propicia o exame de um tema sob novo enfoque ou abordagem, chegando a conclusões inovadoras".

Partindo dos objetivos propostos em analisar as dificuldades do ensino/ aprendizagem de leitura e escrita no Ensino Fundamental do $1^{\circ}$, $2^{\circ}$ e $3^{\circ}$ anos de uma escola pública. $O$ estudo de caso abrange todos os professores da unidade escolar. A técnica utilizada para coleta de dados foi o questionário.

O questionário foi estruturado, seguindo um roteiro previamente estabelecido. Esta pesquisa foi realizada numa escola municipal com todos os envolvidos no processo educativo (8 professores, um diretor, e um coordenador) os quais aceitaram participar do questionário aplicado. 
A pesquisa fundamentou-se em perguntas fechadas e abertas numa sequência lógica de acordo com o tema, problema e objetivos. O questionário forneceu respostas necessárias para a análise da situação, fazendo entender e chegar mais perto possível das dificuldades de aprendizagem. 


\section{CONCLUSÃO}

O estudo revelou alguns equívocos por parte dos professores, como a associação da aula como ambiente de estudo, descuido com a tarefa de casa, excesso de cuidado com planejamento pedagógico e escasso uso de técnicas de estimulação/motivação dos discentes. A pesquisa mostrou, ainda, a falta de autoridade do professor em sala de aula, bem como, dos pais de alunos em relação aos seus filhos. Apesar dos equívocos, a maioria dos professores concorda que a adoção de métodos que estimulem o aluno a aprender é imprescindível para o processo ensino/aprendizagem.

Toda criança possui capacidade cognitiva para aprender a ler e a escrever. O educador precisa entender a dificuldade como um evento natural, cuja causa precisa ser diagnosticada para que o problema seja solucionado. Dificuldade é um sintoma que tem várias origens, assim como a febre, tem que descobrir o motivo dessa dificuldade para que se administre o remédio correto, combatendo a origem do problema.

$\mathrm{Na}$ maioria das vezes, os problemas de aprendizagens não são resolvidos porque o professor foca no ensino e se esquece de ensinar o aluno a estudar em casa. São momentos que ocorrem em tempos diferentes. Aula é para entender, estudo é para aprender, e o sono é para fixar. É necessário resgatar o estudo diário.

Por fim, partindo da premissa de que o conhecimento não é um produto pronto e acabado e que a Educação é direito de todos e dever do Estado e da família, cabe-nos despertar na família a consciência da sua co-responsabilidade na Educação dos seus filhos. 


\section{REFERÊNCIAS BIBLIOGRÁFICAS}

ASSOLA, Camila Fernandes Dourado et all. Metodologia de Alfabetização e letramento em turmas do $1^{\circ}$ e $2^{\circ}$ ano do Ensino Fundamental. V. 4, edição numero 22, de outubro de 2015 a março de 2016.

BOSSA, Nádia A. Dificuldade de Aprendizagem: 0 que são? Como trata-las? Porto Alegre: Artmed, 2013.

BRASIL, Secretaria de Educação Fundamental. Parâmetros Curriculares Nacionais. Introdução aos Parâmetros Curriculares Nacionais. Brasília: MEC/SEF,1997.

BRASIL, Secretaria de Educação Fundamental. Parâmetros Curriculares Nacionais: Língua Portuguesa: Ensino de primeira à quarta série. Brasília, 1997.

FREIRE, Paulo. A Importância do ato de ler em três artigos que se completam. 23를. São Paulo. Cortez, 1989.

FREIRE, Paulo. Pedagogia dos sonhos possíveis. São Paulo, UNESP, 2001.

GADOTTI, Moacir. Boniteza de um sonho: ensinar-e-aprender com sentido. Novo Hamburgo: Feevale, 2003.

LAKATOS, Eva Maria. Marconi, Maria de Andrade. Fundamentos de Metodologia Cientifica. 5 ed. São Paulo. Atlas, 2003.

PIAZZI, Pierluigi. Ensinando inteligência: manual de instruções do cérebro do seu aluno. 2 ed. São Paulo: Aleph, 2014. 